\title{
miR-483-3p regulates acute myocardial infarction by transcriptionally repressing insulin growth factor 1 expression
}

\author{
HAO SUN, JUN CAI, LI XU, JIAMEI LIU, MULEI CHEN, MEILI ZHENG, LEFENG WANG and XINCHUN YANG
}

Heart Center, Beijing Chaoyang Hospital, Capital Medical University, Beijing 100020, P.R. China

Received August 7, 2016; Accepted August 10, 2017

DOI: $10.3892 / \mathrm{mmr} .2018 .8456$

\begin{abstract}
The aim of the present study was to evaluate the functional association between the expression of miR-483-3p and acute myocardial infarction (AMI) in patients and in vitro. $\mathrm{H} 9 \mathrm{c} 2$ cells were incubated in a vacuum with $5 \% \mathrm{CO}_{2}, 5 \% \mathrm{H}_{2}$ and $90 \% \mathrm{~N}_{2}$ for $2 \mathrm{~h}$, which generated the AMI model in vitro. Reverse transcription-quantitative polymerase chain reaction was used to measure miR-483-3p expression, and flow cytometry analysis and ELISA analysis were used to analyze apoptosis rate via caspase- 3 and caspase- 9 activity kits. B-cell lymphoma 2 (Bcl-2)/Bcl-2-associated X protein (Bax) and transcriptionally suppressed the protein expression of insulin growth factor 1 (IGF-1) were analyze using western blot analysis. The results demonstrated that the expression of miR-483-3p in patients with AMI was increased when compared with the control group. In the in vitro model, the overexpression of miR-483-3p promoted apoptosis, increased caspase- 3 and caspase- 9 activity levels, induced the protein expression of Bcl-2/Bax and IGF-1. Picropodophyllotoxin, an IGF-1 inhibitor, was administered to cells following the overexpression of miR-483-3p. Administration of picropodophyllotoxin suppressed IGF-1 protein expression, promoted apoptosis, increased caspase- 3 and caspase- 9 activity levels, and induced the protein expression of $\mathrm{Bax} / \mathrm{Bcl}-2$. The results of the present study revealed that miR-483-3p may regulate AMI via the IGF-1 signaling pathway and may support the restoration of functional performance following AMI.
\end{abstract}

\section{Introduction}

In China, as the levels of air pollution have grown worse, the incidence and mortality rates of environment-associated diseases, such as cardiovascular disease, and the prevalence of adverse health conditions during early human life, such as

Correspondence to: Professor Xinchun Yang, Heart Center, Beijing Chaoyang Hospital, Capital Medical University, 8 Gong-Ti South Road, Beijing 100020, P.R. China

E-mail: gyh940824@126.com

Key words: microRNA-483-3p, acute myocardial infarction, apoptosis, insulin growth factor 1 decreased heart rate variability have increased (1). Coronary heart disease (CHD) is one of the most common environment-associated diseases in the world, with the highest rate of mortality (2). It has been reported that in China, 100 million people succumb to $\mathrm{CHD}$ each year, and approximately half of these deaths are associated with acute myocardial infarction (AMI); thus, AMI is a cardiovascular disease that greatly threatens human health (2). Therefore, further research is required to strengthen the previous basic research performed, and to improve the current prevention and treatment strategies for AMI, in order to protect China's sustainable economic development and improve mortality rates (3). The cause of AMI is complex as a result of the interactions between genes and the environment (3). Heart rate variability reflects the regulation of cardiac rhythm by the autonomic nervous system (4). Epidemiological studies have demonstrated that air pollution can generate a decline in the levels of heart rate variability, which in turn significantly affects the prediction of acute cardiovascular events, such as AMI $(1,2)$.

A previous study revealed that, in several diseases, although the sequences of certain genes are not altered, the modification processes and gene expression are, however, abnormal: This is the focus of epigenetic research (5). Epigenetics is the link between external environmental factors and internal genetic factors (6). Epigenetic dysregulation may result in a variety of diseases, such as cardiovascular disease; microRNAs (miRNAs/miRs) are one of the most important aspects of the epigenetic regulatory mechanism, serving an important role in the occurrence and development of cardiovascular disease (5). A recent study demonstrated that miRNA is involved in the regulation of numerous physiological processes, including the growth and development of the cardiovascular system and angiogenesis (7). At the same time, miRNAs can stably exist in the peripheral blood circulation system (including plasma and serum); circulating miRNAs with disease-characteristic expression profiles are expected to become biomarkers of the disease, with potential clinical value (8). However, the association between plasma miRNA and the risk of AMI requires further epidemiological research $(8,9)$.

Insulin-like growth factor-1 (IGF-1) serves an important role in maintaining homeostatic processes; for example, it has a positive role in the development of myocardial cell growth, primarily regulating protein metabolism and protein synthesis, as well as promoting cell growth and preventing cell death (10). IGF-1 is also involved in a number of physiological 
and pathophysiological processes, including tissue remodeling, glucose and lipid metabolism, and insulin sensitivity (11). In addition, IGF-1 promotes myocardial contraction, improves hemodynamics and energy metabolism, and protects the heart against myocardial apoptosis induced by ischemia or oxidative stress; cardiac-specific overexpression has also been demonstrated (12). IGF-1 in transgenic mice is able to reduce myocardial apoptosis and ventricular pressure, and suppress the expansion of the heart chamber associated with myocardial infarction or increasing age; thus, it serves a vital role in the maintenance of cardiac morphology and function (12). The regulation of IGF-1 levels may improve the overall survival rate in patients with sepsis, which may be realized by strengthening the hepatic clearance of bacterial toxins and improvements to immunity (13). A lack of IGF-1 leads to alterations in body composition, and cytokine and neuroendocrine factor-associated activities. A recent study revealed that IGF-1 deficiency in the heart is able to cause cardiac atrophy and dysfunction (14). Saddic et al (15) reported that miR-483-3p targets may be associated with novel mechanisms mitigating damage caused by ischemic insults on the human heart (15). The aim of the present study was to investigate the functional association between the expression of miR-483-3p and AMI, in patients and in vitro.

\section{Materials and methods}

Study design and patients. Patients with AMI ( $n=6,3$ males and 3 females) and normal volunteers ( $n=6,3$ males and 3 females) were recruited from The Heart Center, Beijing Chaoyang Hospital, Capital Medical University (Beijing, China) during August 2015 to September 2015. Normal volunteers did not have a history of heart disease. Peripheral blood samples $(5 \mathrm{ml})$ were collected and centrifuged at $2,000 \times \mathrm{g}$ for $5 \mathrm{~min}$ at room temperature and stored at $80^{\circ} \mathrm{C}$. The present study was approved by the Heart Center Ethics Committee, Beijing Chaoyang Hospital, Capital Medical University, and written informed consent was obtained from each individual.

Reverse transcription-quantitative polymerase chain reaction $(R T-q P C R)$. Total plasma RNA was isolated from blood and $\mathrm{H} 9 \mathrm{c} 2$ cell samples using TRIzol reagent (Invitrogen; Thermo Fisher Scientific, Inc., Waltham, MA, USA). Total RNA (1-2 $\mu \mathrm{g})$ was reverse-transcribed using the TaqMan microRNA Reverse Transcription kit (Applied Biosystems; Thermo Fisher Scientific, Inc.) according to the manufacturer's protocols. RT-qPCR was performed using the FastStart Universal SYBR Green Master Mix (Roche Diagnostics, Basel, Switzerland) in a 7500 fast Real-Time PCR System (Applied Biosystems; Thermo Fisher Scientific, Inc.). U6, forward ATTGGAACGATA CAGAGAAGATT and reverse GGAACGCTTCACGAA TTTG; miR-483-3p, forward GCTGACTCACTCCTCCCC TC and reverse TATGGTTGTTCACGACTCCTTCAC. The thermocycling conditions were as follows: $95^{\circ} \mathrm{C}$ for $10 \mathrm{~min}$, followed by 40 cycles of $95^{\circ} \mathrm{C}$ for $20 \mathrm{sec}$ and $60^{\circ} \mathrm{C}$ for $30 \mathrm{sec}$. The results were normalized to those of GAPDH and were quantified using the $2^{-\Delta \Delta \mathrm{Cq}}$ method (16). Experiments were performed in triplicate.
H9c 2 cell culture and transfection. $\mathrm{H} 9 \mathrm{c} 2$ cells (70-80\% confluency) were acquired from The Cell Bank of Type Culture Collection of Chinese Academy of Sciences (Shanghai, China) and cultured in Dulbecco's modified Eagle's medium (DMEM; Life Technologies; Thermo Fisher Scientific, Inc.) and 10\% (v/v) fetal bovine serum (Gibco; Thermo Fisher Scientific, Inc.), under an atmosphere of $5 \%(\mathrm{v} / \mathrm{v}) \mathrm{CO}_{2}$ at $37^{\circ} \mathrm{C}$. The miR-483-3p plasmid and negative plasmid were structured and purchased from MyGenostics, Inc. (Beijing, China). H9c2 cells $\left(1 \times 10^{6}\right)$ were seeded into 6-well plates and transfected with the miR-483-3p or negative plasmid (50 nM) using Lipofectamine ${ }^{\circledR} 2000$ (Invitrogen; Thermo Fisher Scientific, Inc.). Following $24 \mathrm{~h}$ after transfection, H9c2 cells were incubated for $2 \mathrm{~h}$ in $5 \% \mathrm{CO}_{2}, 5 \% \mathrm{H}_{2}$ and $90 \% \mathrm{~N}_{2}$, generated by a vacuum; his generated the in vitro AMI model. Following $4 \mathrm{~h}$ after transfection, $\mathrm{H} 9 \mathrm{c} 2$ cells were incubated with $0.5 \mathrm{nM}$ of picropodophyllotoxin for $20 \mathrm{~h}$ at $37^{\circ} \mathrm{C}$, and incubated for $2 \mathrm{~h}$ at $37^{\circ} \mathrm{C}$ in $5 \% \mathrm{CO}_{2}, 5 \% \mathrm{H}_{2}$ and $90 \% \mathrm{~N}_{2}$, generated by a vacuum; this generated the in vitro AMI model. Control group constituted $\mathrm{H} 9 \mathrm{c} 2$ cells that were incubated without picropodophyllotoxin for $2 \mathrm{~h}$ at $37^{\circ} \mathrm{C}$ in $5 \% \mathrm{CO}_{2}, 5 \% \mathrm{H}_{2}$ and $90 \% \mathrm{~N}_{2}$, generated by a vacuum.

Flow cytometry analysis. H9c2 cells $\left(1 \times 10^{6}\right.$ cell/well) were washed with PBS and resuspended with cell apoptosis buffer (Ruisai, Inc., Shanghai, China). H9c2 cells were incubated using the Annexin V-FITC Apoptosis Detection kit (Ruisai, Inc., Shanghai, China) according to the manufacturer's protocols. H9c2 cells $\left(1 \times 10^{4} /\right.$ well) were analyzed by flow cytometric analysis using a BD Accuri C6 flow cytometer and C-Flow Plus v1.0 software (BD Biosciences, Franklin Lakes, NJ, USA) and analyzed uisng Image-ProPlus 6.0 software (Media Cybernetics, Inc., Rockville, MD, USA).

ELISA analysis. Total protein was extracted from H9c2 cells ( $1 \times 10^{3}$ cell/well) using radioimmunoprecipitation (RIPA) lysis buffer (Beyotime Institute of Biotechnology, Haimen, China) on ice for 20-30 min. Protein content was measured using bicinchoninic acid (BCA) lysis buffer (Beyotime Institute of Biotechnology), and $10 \mu \mathrm{g}$ protein was incubated with the caspase-3 (C1116) and caspase-9 (C1158) activity kits (Beyotime Institute of Biotechnology) according to the manufacturer's protocols at $37^{\circ} \mathrm{C}$ for $1 \mathrm{~h}$ for ELISA analysis.

Western blot analysis. Total protein was extracted from H9c2 cells $\left(1 \times 10^{6}\right.$ cell/well) using RIPA lysis buffer (Beyotime Institute of Biotechnology) on ice for 20-30 min. Protein content was then measured using BCA lysis buffer (Beyotime Institute of Biotechnology). Protein (50 $\mu \mathrm{g})$ was subjected to electrophoresis on $8-10 \%$ polyacrylamide SDS gels and transferred onto polyvinylidene fluoride membranes. Membranes were blocked with 5\% non-fat milk in TBST for $1 \mathrm{~h}$ at $37^{\circ} \mathrm{C}$ and preincubated in $5 \%$ non-fat milk prior to incubation with anti-B-cell lymphoma 2 (Bcl-2; 1:1,000, sc-783, Santa Cruz Biotechnology), anti-Bcl-2-associated X protein (Bax; 1:1,000, sc-493, Santa Cruz Biotechnology), anti-IGF (1:2,000, sc-5622, Santa Cruz Biotechnology) and GAPDH (1:2,000, sc-25778, Santa Cruz Biotechnology) overnight at $4^{\circ} \mathrm{C}$, followed by incubation with the peroxidase-conjugated anti-rabbit secondary antibody $(1: 5,000$, 
cat. no. 14708, Cell Signaling Technology, Inc., Danvers, MA, USA). Image J software (National Institutes of Health, Bethesda, MA, USA) was used to quantify protein bands by optical density and visualizated with a BeyoECL Star kit (Beyotime Institute of Biotechnology).

Statistical analysis. The results were expressed as the mean \pm standard error of the mean. The differences between the groups were analyzed using one-way analysis of variance and Tukey's post test. $\mathrm{P}<0.05$ was considered to indicate a statistically significant difference.

\section{Results}

Expression of miR-483-3p in patients with AMI. To identify the expression levels of miR-483-3p in patients with AMI, blood samples were collected from the patients with AMI and the normal volunteers. In patients with AMI, miR-483-3p expression was markedly enhanced when compared with the normal control group (Fig. 1).

Overexpression of miR-483-3p promotes apoptosis in vitro. The miR-483-3p and negative plasmids were transfected in $\mathrm{H} 9 \mathrm{c} 2$ cells, which were then incubated without oxygen to produce the AMI model. As shown in Fig. 2A, presence of the miR-483-3p plasmid significantly increased miR-483-3p expression in the in vitro AMI model. In addition, the miR-483-3p plasmid significantly promoted the rate of apoptosis in the AMI model H9c2 cells (Fig. 2B).

Overexpression of $\mathrm{miR}-483-3 p$ increases caspase-3 and caspase-9 activity in vitro. In vitro, $\mathrm{H} 9 \mathrm{c} 2$ cells overexpressing miR-483-3p were incubated without oxygen, in order to determine the associated apoptotic mechanism of miR-483-3p in AMI. As shown in Fig. 3, caspase-3 and caspase-9 activities were significantly increased in $\mathrm{H} 9 \mathrm{c} 2$ cells transfected with miR-483-3p, when compared with the negative control group.

Overexpression of miR-483-3p increases Bax/Bcl-2 and $I G F-1$ protein expression in vitro. To confirm the roles of miR-483-3p in apoptosis, the expression of IGF-1, Bax and $\mathrm{Bcl}-2$ were investigated in the established in vitro AMI model. Overexpression of miR-483-3p increased $\mathrm{Bax} / \mathrm{Bcl}-2$ and decreased IGF-1 protein expression in vitro, when compared with the negative control group (Fig. 4).

IGF-1 inhibitor increases IGF-1 protein expression in $H 9 c 2$ cells following overexpression of $m i R-483-3 p$. To confirm whether a direct association exists between miR-483-3p and IGF-1 protein expression in AMI, the IGF-1 inhibitor, picropodophyllotoxin, was applied to inhibit IGF-1 expression in the in vitro model of AMI. As shown in Fig. 5, IGF-1 inhibitor significantly suppressed IGF-1 and increased Bax protein expression (and, hence, the $\mathrm{Bax} / \mathrm{Bcl}-2$ ratio) in $\mathrm{H} 9 \mathrm{c} 2$ cells overexpressing miR-483-3p, when compared with H9c2 cells overexpressing miR-483-3p only.

IGF-1 inhibitor promotes apoptosis in H9c2 cells following the overexpression of $m i R-483-3 p$. The present study then

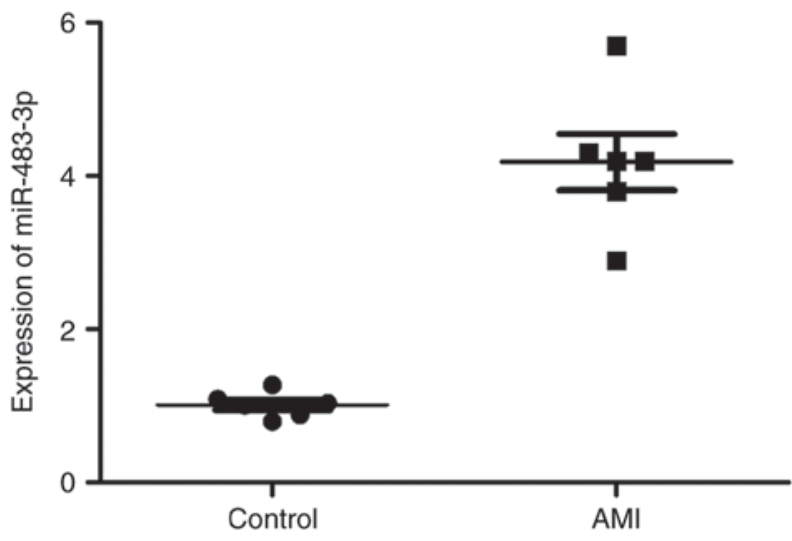

Figure 1. miR-483-3p expression in patients with AMI. Peripheral blood samples were collected from patients with AMI $(n=6)$ and normal control individuals $(n=6)$ for analysis. The expression of miR-483-3p was increased in patients with AMI. miR, microRNA; AMI, acute myocardial infarction; Control, normal control group; AMI, patients with AMI.

investigated the effect of the IGF-1 inhibitor and miR-483-3p overexpression on the regulation of the apoptotic rate in the H9c2 cell model of AMI. As expected, inhibiting IGF-1 expression significantly increased the rate of apoptosis in AMI model H9c2 cells overexpressing miR-483-3p (Fig. 6A). The suppression of IGF-1 expression also significantly increased caspase -3 and -9 activity in $\mathrm{H} 9 \mathrm{c} 2$ cells overexpressing miR-483-3p when compared with miR-483-3p transfection alone (Fig. 6B).

\section{Discussion}

In recent years, environmental pollution has become a serious public health concern, as the rising levels of air pollution pose a serious threat to health, increasing the levels of morbidity and mortality associated with environment-related diseases $(9,17)$. It has been predicted that between the years 2000-2030, the number of the mortalities associated with cardiovascular disease will grow from 5 million to 60 million in developed countries; while in developing countries, it is considered that this fig. will increase from 10 million to 19 million (9). CHD is a chronic, non-communicable disease with the highest mortality rate in the world (18). The World Health Organization has estimated that $\sim 1$ million people succumb to CHD every year, of which AMI accounts for half the mortalities; thus, AMI is a cardiovascular disease considered to be a serious threat to public health, as it is associated with some of the highest recorded rates of morbidity and mortality (19). The present study revealed that miR-483-3p expression was enhanced in patients with AMI, which indicated that miR-483-3p may participate in AMI-induced apoptosis.

The main cause of AMI is associated with coronary artery disease, which is characterized by serious and lasting acute ischemia, or necrosis of the corresponding myocardia induced by the drastic reduction or interruption of coronary blood supply (20). The etiology of AMI is complicated, and this is generally considered to be as a result of the interactions between external environmental factors and genetic factors (21). The sequences of several genes are not altered in the disease state; instead, only modifications to genetic 

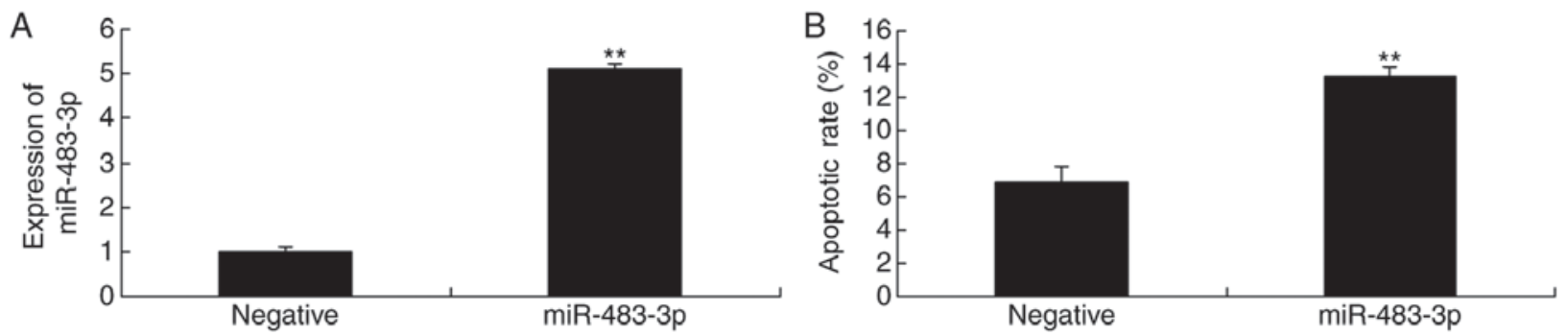

Figure 2. Overexpression of miR-483-3p promoted apoptosis in vitro. H9c2 cells were transfected with either the negative or miR-483-3p plasmid. (A) Overexpression of miR-483-3p promoted the expression of miR-483-3p, as well as (B) the rate of apoptosis in H9c2 cells. ${ }^{* *} \mathrm{P}<0.01$ vs. negative control group. miR, microRNA; Negative group, H9c2 cells + negative control plasmid; miR-483-3p group, H9c2 cells + miR-483-3p plasmid.

processing and gene expression are abnormal: These alternations are known as epigenetic modifications (21). Epigenetics has been an important discovery in the field of medical biology in recent years, and it has enriched our ability to control the phenotypic effect of genes; epigenetics also connects external environmental factors and internal genetic factors, enabling the body to adapt to changes in the environment (22). In recent years, miRNA has become the focus of epigenetic research in the field of cardiovascular disease as an important mechanism of genetic regulation (6). Using an AMI cell model, the present study revealed that the overexpression of miR-483-3p promoted apoptosis and increased the levels of caspase- 3 and -9 activity; therefore, the underlying molecular mechanism of apoptosis in AMI was further investigated.

Apoptosis is an important physiological process that supports biological life and normal activities (23). If the signal transmission pathways that control and regulate apoptosis are severely disrupted, this causes a number of human diseases, including cancer and infectious diseases (24). Cellular factors, including proto-oncogenes, cytokines and $\mathrm{Bcl}-2$ family members, may directly stimulate apoptotic signaling, and important membrane proteins are also associated with apoptosis, controlling apoptosis via different signals inside and outside of the cell (25). A previous study has demonstrated that certain genes, including Bax, p53 and Fas, can promote apoptosis, and other genes, such as Bcl-2 and Bax, are able to inhibit apoptosis (26). The ratio of apoptosis-inducing and apoptosis-inhibiting proteins in vivo is important for determining whether or not apoptosis will proceed; for example, if $\mathrm{Bcl}-2$ protein expression is higher than that of $\mathrm{Bax}$, cell survival is promoted; when Bax expression is higher than that of Bcl-2, apoptosis is accelerated (24). There are notable differences between apoptosis and necrosis in terms of the morphological changes induced, biochemical metabolism and the molecular mechanisms involved. Necrotic cells typically accumulate together to induce cell death, whereas apoptosis is induced by an apoptosis-associated mechanism inside the cell, which is stimulated by specific factors (25). Therefore, it is important to distinguish between the two different cell death phenomena. A significant increase in Bax/Bcl-2 expression in $\mathrm{H} 9 \mathrm{c} 2$ cells overexpressing miR-483-3p was observed in the present study, which indicated that miR-483-3p may serve a key role in promoting apoptosis in AMI.

IGF-1 is a single-chain polypeptide growth factor regulated by hormones that has a high homology with insulin,

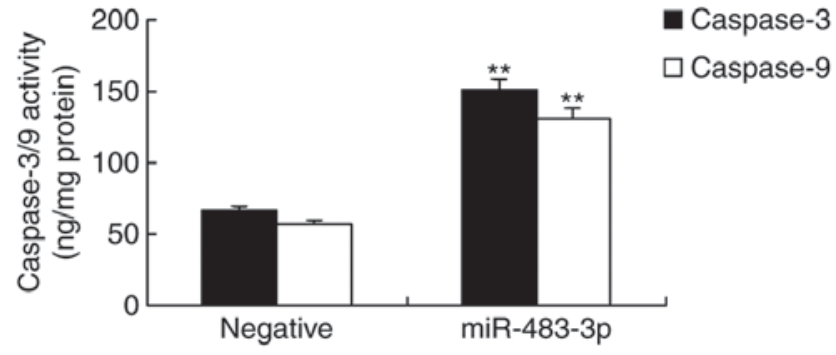

Figure 3. Overexpression of miR-483-3p increased caspase-3 and -9 activities in vitro. ELISA analysis was performed to determine the levels of caspase-3 and -9 activity in $\mathrm{H} 9 \mathrm{c} 2$ cells transfected with a negative or miR-483-3p plasmid. ${ }^{* *} \mathrm{P}<0.01$ vs. negative control group. miR, microRNA; Negative group, H9c2 cells + negative control plasmid; miR-483-3p group, H9c2 cells + miR-483-3p plasmid.

which is involved in cell differentiation, proliferation and insulin-like metabolism (10). The IGF-1 receptor and its binding protein are widely expressed in various tissues, including those of the cardiovascular system (13). It has been established that IGF-1 may participate in a variety of physiological and pathological processes in the heart via endocrine, autocrine and paracrine-associated mechanisms (27). It stimulates the growth of cardiac myocytes, affects cardiac ion channels and enhances myocardial contractility, thereby increasing cardiac output and improving cardiac ejection function (28). The important role of IGF-1 receptors and binding proteins in the developmental process of certain cardiovascular diseases has received increasing interest from researchers. It has been observed that, in cardiac cells overexpressing IGF-1, the sensitivity of filaments to $\mathrm{Ca}^{2+}$ is weakened, the shrinking rate is increased and their compliance is enhanced (29). The decreased sensitivity of filaments to $\mathrm{Ca}^{2+}$ has a negative inotropic effect on damaged cardiac muscle; however, it reduces the energy demand of cardiac decompensation and improves pumping function following heart failure (30). In animal models of myocardial infarction induced by coronary artery ligation, IGF-1 overexpression reduces myocardial cell death and ventricular expansion (31). In a dog model of tachycardia-induced heart failure, IGF-1 reduces the level of cardiomyocyte apoptosis, and enhances cardiac contractile function (31). In the present study, overexpression of miR-483-3p suppressed IGF-1 protein expression, which further promoted the effect of miR-483-3p overexpression on apoptosis in AMI H9c2 cells via the caspase and $\mathrm{Bax} / \mathrm{Bcl}-2$ signaling pathways. 
A

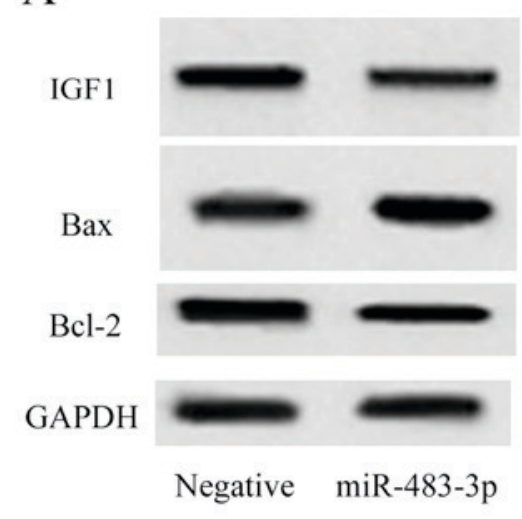

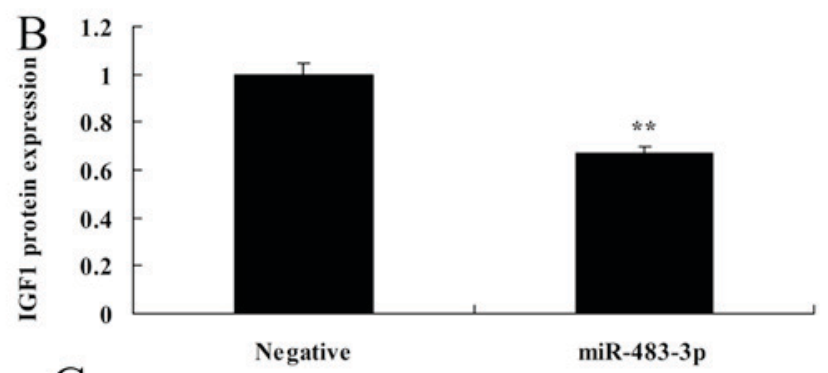

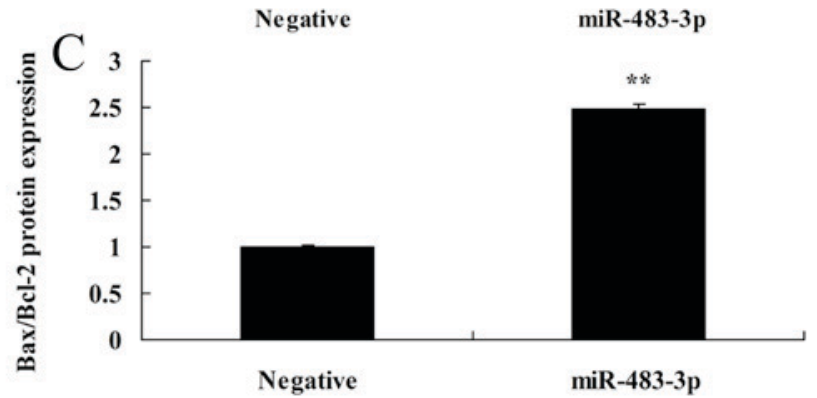

Figure 4. Overexpression of miR-483-3p increased Bax/Bcl-2 and decreased IGF-1 protein expression in vitro. (A) Western blot analysis was performed to determine the protein expression of Bax/Bcl-2 and IGF-1. The results were normalized to those of GAPDH. Overexpression of miR-483-3p (B) significantly decreased IGF-1 protein expression, however, (C) Bax/Bcl-2 protein expression was significantly increased in vitro. ${ }^{* *} \mathrm{P}<0.01$ vs. negative control group. miR, microRNA; Negative group, H9c2 cells + negative control plasmid; miR-483-3p group, H9c2 cells + miR-483-3p plasmid.
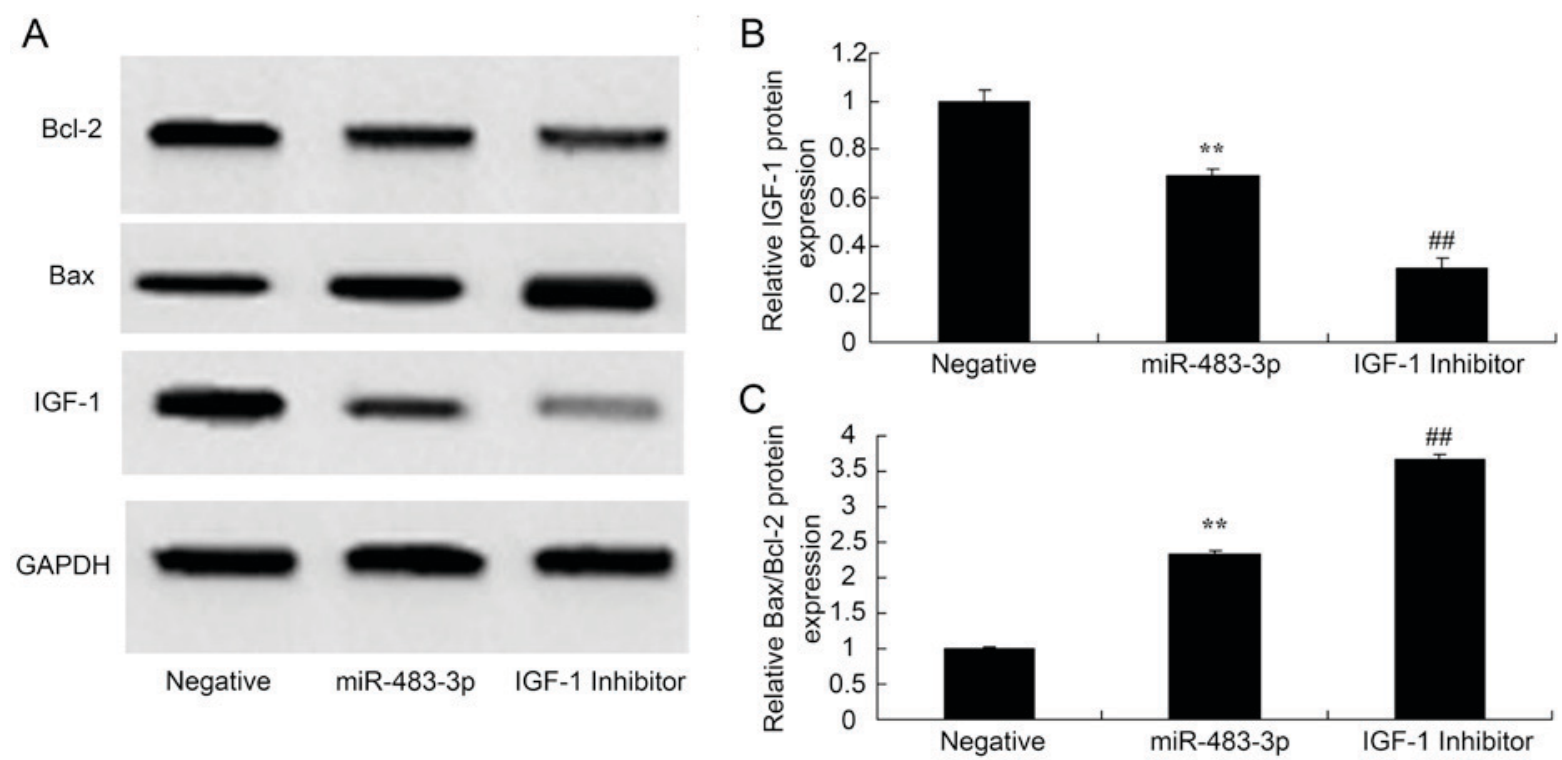

Figure 5. IGF-1 inhibitor decreased IGF-1 and increased Bax/Bcl-2 protein expression in H9c2 cells overexpressing miR-483-3p. (A) Western blotting assays were performed to determine the effect of the IGF-1 inhibitor on IGF-1 and Bax/Bcl-2 protein expression. The results were normalized to those of GAPDH. The expression of (B) IGF-1 was significantly decreased; however, (C) Bax/Bcl-2 protein expression increased in H9c2 cells overexpressing miR-483-3p. ${ }^{* *} \mathrm{P}<0.01$ vs. negative control group; ${ }^{\# \#} \mathrm{P}<0.01$ vs. miR-483-3p group. miR, microRNA; Negative group, H9c2 cells + negative control plasmid; miR-483-3p group, $\mathrm{H} 9 \mathrm{c} 2$ cells + miR-483-3p plasmid.
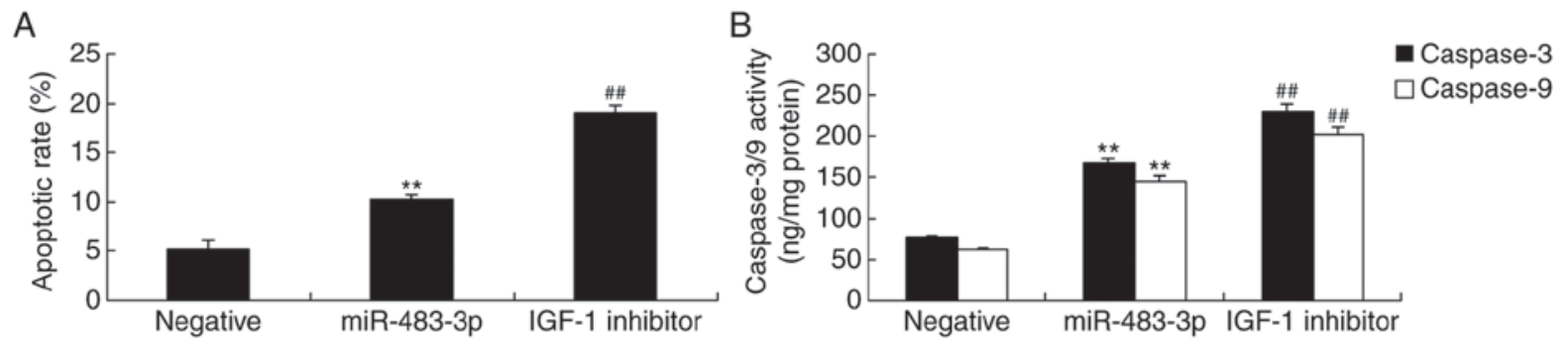

Figure 6. IGF-1 inhibitor promoted apoptosis, and caspase-3 and -9 activities in H9c2 cells overexpressing miR-483-3p. The IGF-1 inhibitor promoted (A) apoptosis, and (B) caspase-3 and -9 activities in $\mathrm{H} 9 \mathrm{c} 2$ cells overexpressing miR-483-3p. ${ }^{* *} \mathrm{P}<0.01$ vs. negative control group; ${ }^{\# \#} \mathrm{P}<0.01$ vs. miR-483-3p group. miR, microRNA; Negative group, H9c2 cells + negative control plasmid; miR-483-3p group, H9c2 cells + miR-483-3p plasmid. 
In conclusion, the significant results of the present study demonstrated that the overexpression of miR-483-3p promoted apoptosis, increased caspase- 3 and -9 activity levels, and induced the protein expression of $\mathrm{Bax} / \mathrm{Bcl}-2$ in the AMI model. These results may contribute towards the identification of a potential therapeutic target of IGF-1 in AMI-induced apoptosis.

\section{References}

1. Thiele H, Desch S, Piek JJ, Stepinska J, Oldroyd K, Serpytis P, Montalescot G, Noc M, Huber K, Fuernau G et al: Multivessel versus culprit lesion only percutaneous revascularization plus potential staged revascularization in patients with acute myocardial infarction complicated by cardiogenic shock: Design and rationale of CULPRIT-SHOCK trial. Am Heart J 172: 160-169, 2016.

2. Cerisano G, Buonamici P, Valenti R, Moschi G, Taddeucci E, Giurlani L, Migliorini A, Vergara R, Parodi G, Sciagrà R, et al: Effects of a timely therapy with doxycycline on the left ventricular remodeling according to the pre-procedural TIMI flow grade in patients with ST-elevation acute myocardial infarction. Basic Res Cardiol 109: 412, 2014.

3. Wang HL, Xing SY, Dong PS, Han YH, Zhu JH, Lai LH and Zhao JF: Safety and efficacy of intracoronary tirofiban administration in patients with serious thrombus burden and ST-elevation myocardial infarction undergoing percutaneous coronary intervention. Eur Rev Med Pharmacol Sci 18: 3690-3695, 2014.

4. Dohi T, Maehara A, Brener SJ, Généreux P, Gershlick AH, Mehran R, Gibson CM, Mintz GS and Stone GW: Utility of peak creatine kinase-MB measurements in predicting myocardial infarct size, left ventricular dysfunction, and outcome after first anterior wall acute myocardial infarction (from the INFUSE-AMI trial). Am J Cardiol 115: 563-570, 2015.

5. Matsumoto S, Sakata Y, Suna S, Nakatani D, Usami M, Hara M, Kitamura T, Hamasaki T, Nanto S, Kawahara Y and Komuro I: Circulating p53-responsive microRNAs are predictive indicators of heart failure after acute myocardial infarction. Circ Res 113: 322-326, 2013.

6. Biasucci LM and Cardillo MT: MicroRNA and myocardial infarction: A mystery turning into glory? J Am Coll Cardiol 62: 999-1001, 2013.

7. Huang W, Tian SS, Hang PZ, Sun C, Guo J and Du ZM: Combination of microRNA-21 and microRNA-146a attenuates cardiac dysfunction and apoptosis during acute myocardial infarction in mice. Mol Ther Nucleic Acids 5: e296, 2016.

8. Eryilmaz U, Akgüllü C, Beşer N, Yıldız Ö, Kurt Ömürlü İ and Bozdoğan B: Circulating microRNAs in patients with ST-elevation myocardial infarction. Anatol J Cardiol 16: 392-396, 2016.

9. Marfella R, Sasso FC, Siniscalchi M, Paolisso P, Rizzo MR, Ferraro F, Stabile E, Sorropago G, Calabrò P, Carbonara $\mathrm{O}$, et al: Peri-procedural tight glycemic control during early percutaneous coronary intervention is associated with a lower rate of in-stent restenosis in patients with acute ST-elevation myocardial infarction. J Clin Endocrinol Metab 97: 2862-2871, 2012.

10. Ketha $\mathrm{H}$ and Singh RJ: Clinical assays for quantitation of insulin-like-growth-factor-1 (IGF1). Methods 81: 93-98, 2015.

11. Jackson R, Tilokee EL, Latham N, Mount S, Rafatian G, Strydhorst J, Ye B, Boodhwani M, Chan V, Ruel M, et al: Paracrine engineering of human cardiac stem cells with insulin-like growth factor 1 enhances myocardial repair. J Am Heart Assoc 4: e002104, 2015.

12. Nelson DM, Hashizume R, Yoshizumi T, Blakney AK, Ma Z and Wagner WR: Intramyocardial injection of a synthetic hydrogel with delivery of bFGF and IGF1 in a rat model of ischemic cardiomyopathy. Biomacromolecules 15: 1-11, 2014.

13. Ge RT, Mo LH, Wu R, Liu JQ, Zhang HP, Liu Z, Liu Z and Yang PC: Insulin-like growth factor-1 endues monocytes with immune suppressive ability to inhibit inflammation in the intestine. Sci Rep 5: 7735, 2015.

14. Krieger F, Elflein N, Saenger S, Wirthgen E, Rak K, Frantz S, Hoeflich A, Toyka KV, Metzger F and Jablonka S: Polyethylene glycol-coupled IGF1 delays motor function defects in a mouse model of spinal muscular atrophy with respiratory distress type 1. Brain 137: 1374-1393, 2014.
15. Saddic LA, Chang TW, Sigurdsson MI, Heydarpour M, Raby BA, Shernan SK, Aranki SF, Body SC and Muehlschlegel JD: Integrated microRNA and mRNA responses to acute human left ventricular ischemia. Physiol Genomics 47: $455-462,2015$

16. Livak KJ and Schmittgen TD: Analysis of relative gene expression data using real-time quantitative PCR and the 2(-Delta Delta C(T)) method. Methods 25: 402-408, 2001.

17. Gao LR, Chen Y, Zhang NK, Yang XL, Liu HL, Wang ZG, Yan XY, Wang Y, Zhu ZM, Li TC, et al: Intracoronary infusion of Wharton's jelly-derived mesenchymal stem cells in acute myocardial infarction: Double-blind, randomized controlled trial. BMC Med 13: 162, 2015.

18. Tan NS, Goodman SG, Cantor WJ, Tan MK, Yan RT, Bagnall AJ, Mehta SR, Fitchett D, Strauss BH and Yan AT; TRANSFER-AMI Investigators: Comparison of the efficacy of pharmacoinvasive management for ST-segment elevation myocardial infarction in smokers versus non-smokers (from the Trial of Routine Angioplasty and Stenting After Fibrinolysis to Enhance Reperfusion in Acute Myocardial Infarction). Am J Cardiol 114: 955-961, 2014.

19. Minamisawa M, Izawa A, Motoki H, Kashima Y, Hioki H, Abe N, Miura T, Ebisawa S, Miyashita Y, Koyama J and Ikeda U: Prognostic significance of neuroadrenergic dysfunction for cardiovascular events in patients with acute myocardial infarction. Circ J 79: 2238-2245, 2015.

20. Weinreuter M, Kreusser MM, Beckendorf J, Schreiter FC, Leuschner F, Lehmann LH, Hofmann KP, Rostosky JS, Diemert N, Xu C, et al: CaM Kinase II mediates maladaptive post-infarct remodeling and pro-inflammatory chemoattractant signaling but not acute myocardial ischemia/reperfusion injury. EMBO Mol Med 6: 1231-1245, 2014.

21. Rios E, Mancio J, Rodrigues-Pereira P, Magalhães D and Bartosch C: Large myocardial infarction with myocardium calcium deposits associated with reperfusion injury. Cardiovasc Pathol 23: 379-380, 2014

22. Rayner K, Dimmeler S, Calin GA, Thum T, Raizman JE and Diamandis EP: Novel biomarkers for acute myocardial infarction: Is microRNA the new kid on the block? Clin Chem 60: 812-817, 2014.

23. Ma LN, Li LD, Li SC, Hao XM, Zhang JY, He P and Li YK: Allicin improves the cardiac function by protecting against apoptosis in rat model of myocardial infarction. Chin J Integr Med 23: 589-597, 2017.

24. Ueda S, Yamagishi S, Matsui T, Jinnouchi Y and Imaizumi T: Administration of pigment epithelium-derived factor inhibits left ventricular remodeling and improves cardiac function in rats with acute myocardial infarction. Am J Pathol 178: 591-598, 2011.

25. Wang Y, Zhang H, Chai F, Liu X and Berk M: The effects of escitalopram on myocardial apoptosis and the expression of Bax and $\mathrm{Bcl}-2$ during myocardial ischemia/reperfusion in a model of rats with depression. BMC Psychiatry 14: 349, 2014.

26. Malick M, Gilbert K, Barry M, Godbout R and Rousseau G: Desvenlafaxine reduces apoptosis in amygdala after myocardial infarction. Brain Res Bull 109: 158-163, 2014.

27. Huang Y, Harrison MR, Osorio A, Kim J, Baugh A, Duan C, Sucov HM and Lien CL: Igf signaling is required for cardiomyocyte proliferation during zebrafish heart development and regeneration. PLoS One 8: e67266, 2013.

28. Sengupta A, Kalinichenko VV and Yutzey KE: FoxO1 and FoxM1 transcription factors have antagonistic functions in neonatal cardiomyocyte cell-cycle withdrawal and IGF1 gene regulation. Circ Res 112: 267-277, 2013.

29. Anversa P, Reiss K, Kajstura J, Cheng W, Li P, Sonnenblick EH and Olivetti G: Myocardial infarction and the myocyte IGF1 autocrine system. Eur Heart J 16 (Suppl N): S37-S45, 1995.

30. Andreassen M, Raymond I, Kistorp C, Hildebrandt P, Faber J and Kristensen LØ: IGF1 as predictor of all cause mortality and cardiovascular disease in an elderly population. Eur J Endocrinol 160: 25-31, 2009.

31. Lai CH, Ho TJ, Kuo WW, Day CH, Pai PY, Chung LC, Liao PH, Lin FH, Wu ET and Huang CY: Exercise training enhanced SIRT1 longevity signaling replaces the IGF1 survival pathway to attenuate aging-induced rat heart apoptosis. Age (Dordr) 36: 9706, 2014. 